11

\title{
Исследование параметров прозрачных токопроводящих периодических структур, изготовленных методом лазерной абляции
}

\author{
(ㄱ С.А. Остриков, П.А. Носов , П.А. Михалёв, М.О. Макеев, А.С. Проваторов, А.В. Корольков \\ Московский государственный технический университет им. Н.Э. Баумана, \\ 105005 Москва, Россия \\ e-mail: ostrikovsergey99@yandex.ru, `pan@bmstu.ru
}

Поступила в редакцию 20.12.2021 г.

В окончательной редакции 20.12.2021 г.

Принята к публикации 30.12.2021 г.

Приведены результаты исследования прозрачного в широком диапазоне длин волн 550-2000 nm сетчатого электрода с низким электрическим сопротивлением из алюминиевой пленки толщиной $30 \mu \mathrm{m}$ на полиимидной подложке толщиной $20 \mu \mathrm{m}$, изготовленного методом лазерной абляции. Метод реализуется при помощи волоконного иттербиевого наносекундного лазера с длиной волны излучения $1064 \mathrm{~nm}$. Полученная структура имеет коэффициент пропускания $>50 \%$ в обозначенном диапазоне спектра и электрическое сопротивление $<1.5 \Omega /$ sq.

Ключевые слова: прозрачные электроды, токопроводящие периодические структуры, лазерная абляция, импульсное лазерное излучение, волоконный лазер, лазерная оптика, лазерные технологии.

DOI: $10.21883 / \mathrm{OS} .2022 .04 .52273 .49-21$

\section{Введение}

Металлические периодические (сетчатые) структуры могут использоваться в качестве прозрачных токопроводящих электродов в таких оптоэлектронных устройствах, как жидкокристаллические дисплеи [1], дисплеи на основе органических светодиодов (OLEDs) [2], сенсорные панели [3], солнечные модули идр. Такие структуры с периодически повторяющимися „окнами“ прозрачности должны обладать как высоким пропусканием оптического излучения и низким электрическим сопротивлением, так и большой гибкостью и механической прочностью, поскольку в большинстве современных устройств необходим непосредственный механический контакт с пленочным сетчатым электродом, который должен быть устойчив к внешним воздействиям. Поэтому в настоящее время помимо традиционного оксида индия-олова (ITO), прозрачного в видимой области спектра, но в то же время хрупкого, обрабатываемого на производстве с большим количеством отходов, дорогого и редкого материала, разрабатывают прозрачные электроды из альтернативных материалов. К ним относятся углеродные нанотрубки [4], оксид цинка, легированный бором ( $\mathrm{ZnO}: \mathrm{B})$ [5] или алюминием ( $\mathrm{ZnO}: \mathrm{Al})$ [6], оксид олова, легированный фтором $\left(\mathrm{SnO}_{2}: \mathrm{F}\right)$, оксид кадмия, легированный индием $(\mathrm{CdO}: \mathrm{In})$, чистые металлы: серебpo $(\mathrm{Ag})$, алюминий $(\mathrm{Al})$, медь $(\mathrm{Cu})[7]$ и др.

На сегодняшний день применяют различные методы изготовления прозрачных токопроводящих сетчатых структур [8]. Так, исследователям, использовавшим технологию селективного лазерного спекания коллоидного серебра, удалось установить, что при размере ячейки $>300 \mu \mathrm{m}$ можно получить коэффициент пропускания $\geq 85 \%$ и сопротивление $\leq 30 \Omega /$ sq для сетчатой струк- туры $50 \times 50 \mathrm{~mm}$ с квадратными окнами прозрачности и проводниками толщиной $11-12 \mu \mathrm{m}$ [3]. Медная прозрачная структура, изготовленная методом электроспиннингования полимерных волокон с последующим напылением металла, имела коэффициент пропускания 90\% при сопротивлении $2 \Omega / \mathrm{sq}$ [9]. В работе [10], применяя струйную печать, получили двухслойный прозрачный электрод, состоящий из серебряной сетки и слоя ITO; при ширине квадратной ячейки $300 \mu \mathrm{m}$ и толщине серебряного проводника $7.5 \mu \mathrm{m}$ были достигнуты коэффициент пропускания $83.25 \%$ и сопротивление $1.4 \Omega / \mathrm{sq}$. Фотолитографию также применяли для изготовления прозрачной металлической структуры. Удалось добиться коэффициента пропускания около $54.2 \%$ в видимом диапазоне спектра и сопротивления $2.2 \Omega$ /sq для серебряной сетки толщиной $200 \mathrm{~nm}$, покрытой слоем ITO толщиной $30 \mathrm{~nm}$, при расстоянии между двумя соседними проводниками около $200 \mu \mathrm{m}$ [11]. Структура с периодически повторяющимися проводниками, полученная путем наложения гибкого полидиметилсилоксанового штампа с медными проводниками на подложку из полиэтилендиокситиофеном : полистиролсульфонатом (PEDOT : PSS), имела коэффициент пропускания 80\% и сопротивление $9.3 \Omega / \mathrm{sq}[12]$. Применив лазерную абляцию для изготовления прозрачного электрода, специалисты получили медную структуру $36 \times 36 \mathrm{~mm}$ с большим количеством отверстий диаметром $150 \mu \mathrm{m}$, коэффициент пропускания которой достигал 67\%, сопротивление было около $20 \Omega / \mathrm{sq}$ [7].

Из всех вышеперечисленных методов изготовления прозрачных токопроводящих периодических структур стоит выделить электроспиннингование волокна с последующим напылением металла, так как с помощью этой технологии удалось получить самые высокие значения 


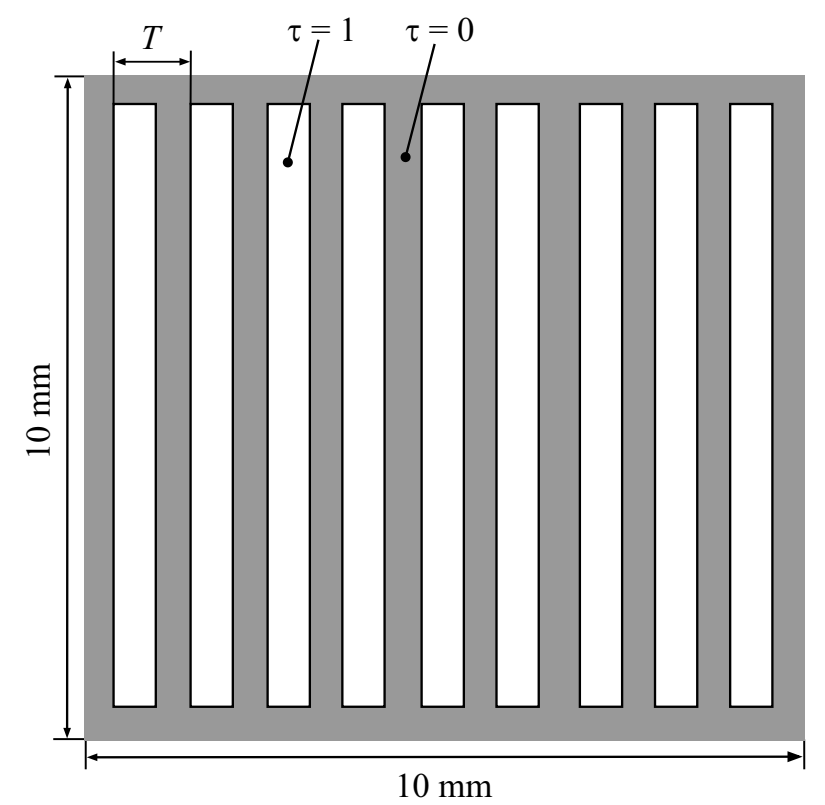

Рис. 1. Макет периодической структуры. $T$ - период.

коэффициента пропускания и электрической проводимости [9]. Однако в последнее время для создания сетчатых электродов больших размеров исследователями рассматривается применение метода лазерной абляции из-за его сравнительно низкой стоимости и простоты, а также высокой скорости обработки. В настоящей работе рассматривается возможность изготовления прозрачной токопроводящей сетчатой структуры из Al, нанесенного на полиимидную (PI) подложку, методом лазерной абляции с помощью лазерного гравера, работающего в наноимпульсном режиме.

\section{Экспериментальная часть}

Процесс изготовления прозрачной токопроводящей периодической структуры из Al-пленки состоит из двух этапов. Первый этап заключается в разработке рисункамакета будущей сетчатой структуры в графическом редакторе. В нашем исследовании рисунок-макет структуры представляет собой квадрат со стороной $10 \mathrm{~mm}$, в котором расположены повторяющиеся линии с периодом следования $T$ (рис. 1). На рис. 1 белым цветом обозначены области, подвергающиеся лазерной абляции, а серым цветом - область остаточного металла. Второй этап - это непосредственно сам процесс нанесения разработанного рисунка на Al-пленку посредством лазерной абляции при помощи лазерного гравера PEDB-400B. В качестве источника излучения будем применять волоконный ИК лазер, который широко применяется в лазерных системах и технологиях [13-17].

Лазерный гравер PEDB-400B, который применяется в нашем исследовании для изготовления прозрачной Al-структуры на PI-подложке, включает следующие основные элементы: иттербиевый $(\mathrm{Yb})$ волоконный лазер с длиной волны излучения $\lambda=1064 \mathrm{~nm}$, сканирующая головка, обеспечивающая сканирование лазерного пучка по обрабатываемой поверхности при помощи двух зеркал, установленных на гальванометрах. Лазер имеет диапазон изменения выходной мощности $10-30 \mathrm{~W}$, диапазон изменения частоты повторения импульсов $20-80 \mathrm{kHz}$, длительность импульса $100 \mathrm{~ns}$. Сканирующая головка позволяет сканировать поверхность со скоростью до $7000 \mathrm{~mm} / \mathrm{s}$. Процесс работы лазерного гравера осуществляется под управлением персонального компьютера, с помощью которого можно изменять параметры лазера и скорость сканирования. Для фокусировки лазерного пучка на обрабатываемой поверхности применяется F-Theta-объектив SL-1064-112-163G с задним фокусным расстоянием $163 \mathrm{~mm}$, поле зрения которого в пространстве изображений характеризуется максимальной площадью объекта $112 \times 112 \mathrm{~mm}$. F-Thetaобъектив, в отличие от одиночной сферической линзы, не вносит кривизну поля и позволяет фокусировать внеосевые пучки, распространяющиеся под разными углами к оптической оси объектива, на обрабатываемой поверхности. Используемый нами объектив позволяет получить диаметр перетяжки лазерного пучка $\sim 40 \mu \mathrm{m}$.

В нашем исследовании проводятся эксперименты по изготовлению прозрачных токопроводящих периодических структур площадью $10 \times 10 \mathrm{~mm}$ из Al-пленки толщиной $30 \mu \mathrm{m}$, нанесенной на РІ-подложку толщиной $20 \mu \mathrm{m}$, методом лазерной абляции с длительностью импульсов лазера $100 \mathrm{~ns}$. Для уменьшения механических деформаций Al-пленки, вызванных неравномерным нагревом материала под воздействием лазерного излучения, под образец подкладывается стальная пластина, а сверху образца устанавливаются неодимовые магниты по контуру обрабатываемого участка $10 \times 10 \mathrm{~mm}$ (рис. 2). Магниты поджимают Al-пленку, тем самым повышая качество получаемой сетчатой структуры.

В нашем исследовании для измерения пропускания оптического излучения в широком спектральном диапазоне 350-2000 nm с шагом $2 \mathrm{~nm}$ используется спектрофотометр Shimadzu UV-3600i Plus с интегрирующей сферой с разрешением $1 \mathrm{~nm}$ при нормальном падении света на образец. Интегрирующая сфера позволяет производить оценку пропускания по полному проходящему потоку через образец. Измерение пропускания проводится в нескольких локальных частях образца, а пропускание сетчатой структуры рассчитывается как среднее значение. Для детального изучения топологии изготавливаемых прозрачных сетчатых структур используем стереомикроскоп Leica s9i. Поверхностное сопротивление определяется четырёхзондовым методом с применением мультиметра Keithley 2000 и четырёхзондовой головки Mill-Max 854-22-004-10-001101.

При частоте повторения импульсов $50 \mathrm{kHz}$, выходной мощности лазера $27 \mathrm{~W}, 45$ проходах лазерного пучка со скоростью сканирования $4000 \mathrm{~mm} / \mathrm{s}$ удается получить сетчатые структуры с $T \approx 70,80,90 \mu \mathrm{m}$ (рис. 3 ). Такие структуры представляют массивы микролиний, где тол- 


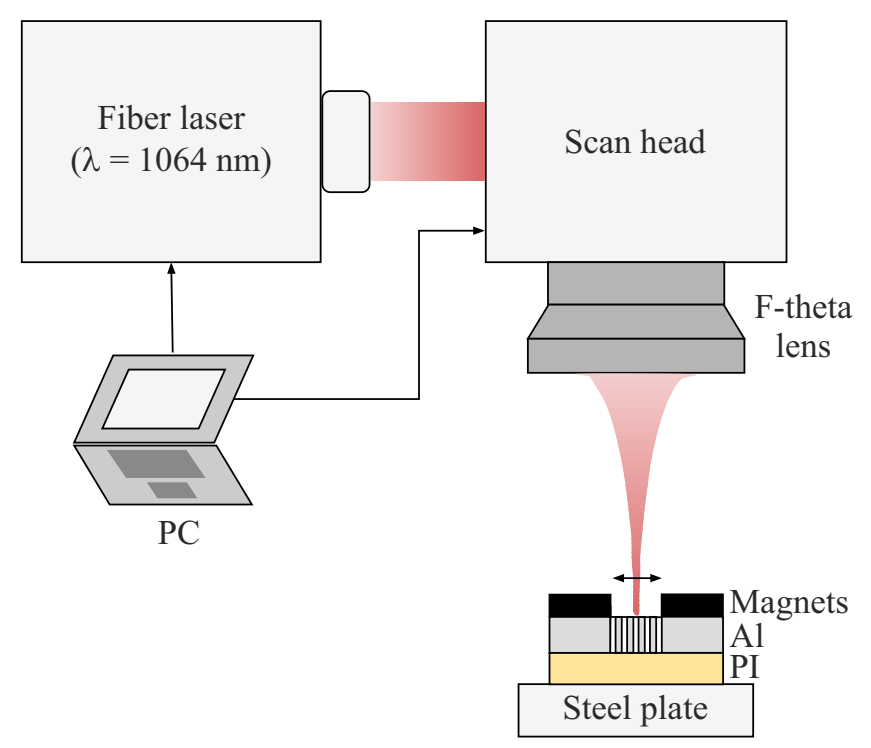

Рис. 2. Схема экспериментальной установки.

щина удаляемой линии составляет $\sim 40 \mu \mathrm{m}$, что соответствует техническим характеристикам используемого F-Theta-объектива.

В нашем исследовании также проводится эксперимент по созданию прозрачных сетчатых структур при изменении скорости сканирования и количества проходов лазерного пучка по обрабатываемой поверхности. Сначала 15 раз со скоростью сканирования $4000 \mathrm{~mm} / \mathrm{s}$ осуществляется лазерная обработка, затем 25 раз со скоростью $6000 \mathrm{~mm} / \mathrm{s}$. В результате такого перехода к „легкому“ режиму обработки удается получить сетчатые структуры без шероховатых участков на поверхности с $T \approx 70,80,90 \mu \mathrm{m}$ (рис. 4 ).

Для измерения коэффициента пропускания прозрачной токопроводящей сетчатой структуры необходимо понимать, что в нашем исследовании используется Alпленка, нанесенная на РІ-подложку толщиной $20 \mu \mathrm{m}$. Для того чтобы убрать слой $\mathrm{Al}$ и затем измерить спектр пропускания только РІ-подложки (рис. 5), необходимо воспользоваться лазерным гравером. Измерив спектры пропускания в диапазоне длин волн 350-2000 nm PI-подложки и двухслойного образца, можно построить спектр пропускания прозрачной периодической Alструктуры, воспользовавшись формулой для вычисления спектрального коэффициента пропускания Al-структуры:

$$
\tau_{\lambda \mathrm{Al}}(\lambda)=\frac{\tau_{\lambda}(\lambda)}{\tau_{\lambda \mathrm{PI}}(\lambda)} \cdot 100 \%,
$$

где $\tau_{\lambda}(\lambda)-$ спектральный коэффициент пропускания двухслойного образца, $\tau_{\lambda \mathrm{PI}}(\lambda)-$ спектральный коэффициент пропускания полиимидной подложки.

\section{Результаты и их обсуждение}

Результатом проведения первого эксперимента является получение прозрачных токопроводящих пери-
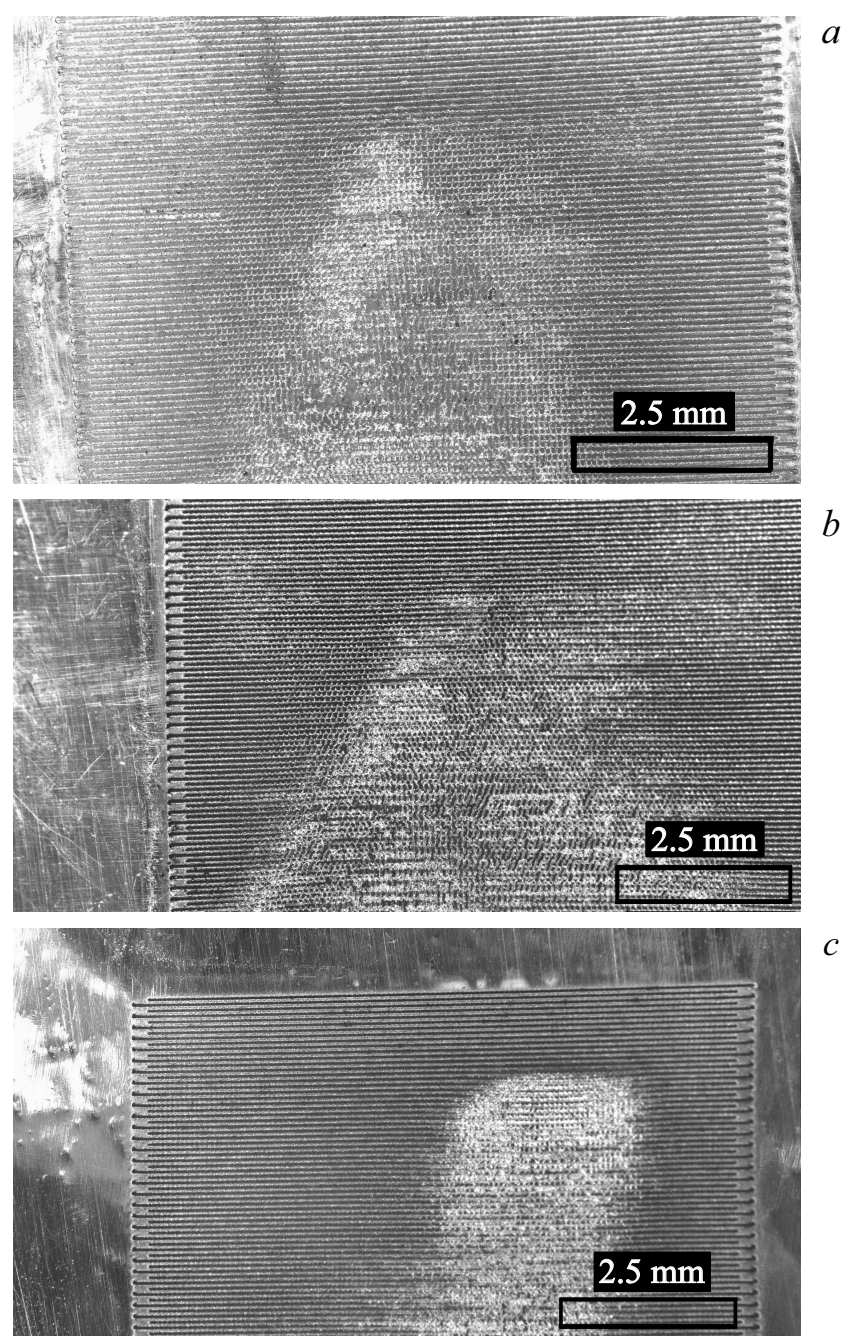

Рис. 3. Полученные в I эксперименте структуры с периодом $T$ $70 \mu \mathrm{m}(a), 80 \mu \mathrm{m}(b), 90 \mu \mathrm{m}(c)$.

одических структур в виде массива микролиний с $T=70,80,90 \mu \mathrm{m}$ (рис. 3). Видно, что изготовленные структуры имеют в центре достаточно большие шероховатые участки, которые являются результатом выхода из абляционных кратеров расплавленного Al на поверхность. Если высота неровностей поверхности превышает длину волны падающего излучения, то возникает диффузное рассеяние и, как следствие, уменьшение коэффициента пропускания. Так, коэффициент пропускания в видимой области спектра сетчатой структуры с $T=90 \mu \mathrm{m}$, который удалось получить по результатам первого эксперимента, равен $34.98 \%$ на длине волны $\lambda=555 \mathrm{~nm}$ (рис. $5, a)$. Также удалось изготовить сетчатую структуру с $T=70 \mu \mathrm{m}$, коэффициент пропускания которой на длине волны $\lambda=555 \mathrm{~nm}$ равен $33.26 \%$, а максимальный коэффициент пропускания в ближней инфракрасной области спектра равен $50 \%(\lambda=1950 \mathrm{~nm})$.

В целях уменьшения шероховатости поверхности и получения сетчатой структуры с большим пропусканием было принято решение уменышить длительность воз- 


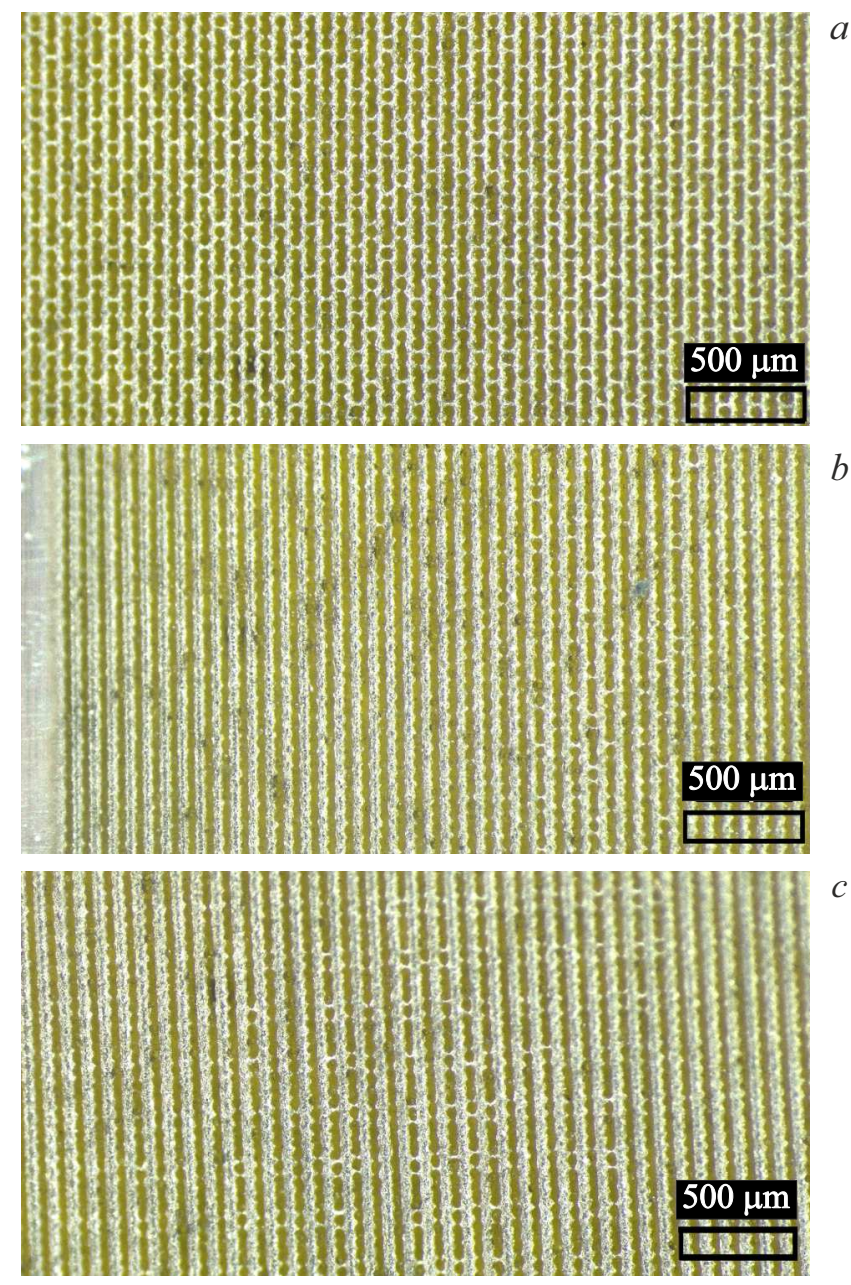

Рис. 4. Полученные во II эксперименте структуры с периодом $70 \mu \mathrm{m}(a), 80 \mu \mathrm{m}(b), 90 \mu \mathrm{m}(c)$.

действия лазерного излучения на $\mathrm{Al}$ путем изменения количества проходов и скорости сканирования лазерного пучка. В результате удалось изготовить высококачественные прозрачные токопроводящие сетчатые структуры с большим пропусканием оптического излучения по сравнению с пропусканием сетчатых структур с шероховатыми участками. Так, коэффициент пропускания сетчатой структуры с $T=70 \mu \mathrm{m}$ превышает $50 \%$ в диапазоне длин волн 550-2000 nm (рис. 5,b). Также можно заметить, что пропускание оптического излучения уменьшается при увеличении $T$ за счет уменьшения количества окон прозрачности и увеличения площади остаточного металла. В нашем исследовании также была выявлена зависимость электрического сопротивления прозрачной сетчатой структуры от периода повторения микролиний $T$. При изменении $T$ от 70 до $90 \mu \mathrm{m}$ электрическое сопротивление уменьшается от $\sim 1.4$ до $1.07 \Omega / \mathrm{sq}$.

Предполагается, что вид топологии структуры влияет на ее параметры. Поэтому для получения прозрачных токопроводящих сетчатых структур с более высоким значением коэффициента пропускания необходимо разработать другой рисунок-макет, а также использовать другие материалы в качестве токопроводящего слоя.

Стоит отметить, что метод лазерной абляции, применяемый в представленных экспериментах, и лазерный гравер PEDB-400B подойдут для изготовления больших сетчатых структур. Площадь образца определяется исключительно рабочим полем F-Theta-объектива, который можно при необходимости заменить. В нашем случае применяется объектив с рабочим полем $112 \times 112 \mathrm{~mm}$, соответственно максимальная площадь возможной сетчатой структуры, изготовленной с помощью данного объектива, равна $12544 \mathrm{~mm}^{2}$. Помимо того что метод лазерной абляции позволяет получать структуры больших размеров, он обеспечивает высокую скорость их изготовления. В отличие от дорогих и многоэтапных технологий [3,9-12] технологический процесс изготовления прозрачных токопроводящих периодических структур методом лазерной абляции состоит всего из 3 стадий: разработка топологии будущей структуры, лазерная обработка и контроль параметров полученной структуры. Это свидетельствует о том, что процесс изготовления
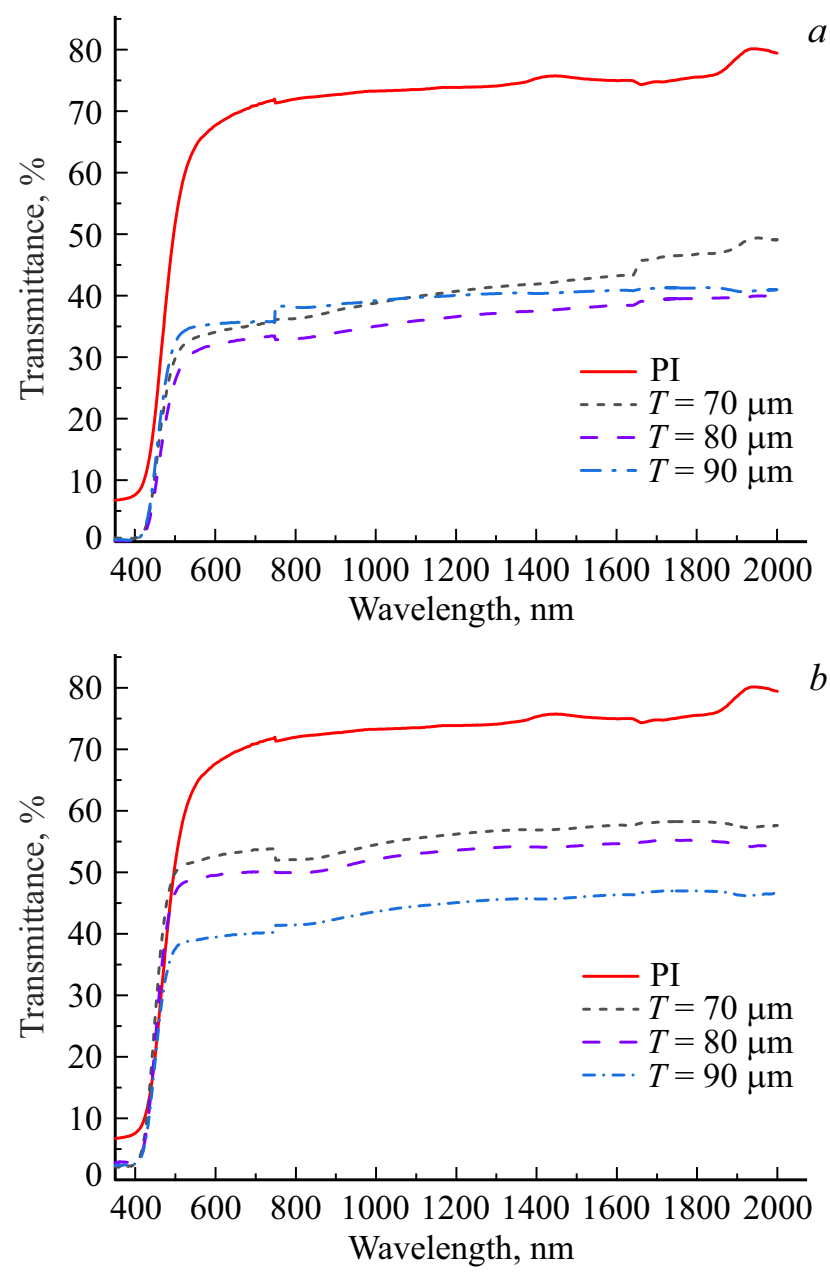

Рис. 5. Спектры пропускания прозрачных токопроводящих периодических структур, полученных в I $(a)$ и во II экспериментах $(b)$. 
сетчатых структур методом лазерной абляции осуществляется значительно быстрее по времени, чем другими методами.

\section{Заключение}

В ходе настоящей работы удалось изготовить методом лазерной абляции прозрачные токопроводящие периодические структуры $10 \times 10 \mathrm{~mm}$ высокого качества из Al-пленки толщиной $30 \mu \mathrm{m}$, нанесенной на PIподложку толщиной $20 \mu \mathrm{m}$. Из полученных структур следует выделить сетчатую структуру с периодом повторения микролиний $T=70 \mu \mathrm{m}$, у которой коэффициент пропускания оптического излучения $>50 \%$ в диапазоне длин волн $\lambda=550-2000 \mathrm{~nm}$, а электрическое сопротивление $\sim 1.4 \Omega /$ sq. Такую структуру можно использовать в качестве прозрачного проводника в оптоэлектронных устройствах, работающих в видимом и ближнем инфракрасном диапазонах спектра.

На основе полученных результатов и данных работ [3,9-12] сделан вывод о том, что лазерная абляция является высокопроизводительным методом изготовления прозрачных токопроводящих периодических структур из различных материалов. Также данная лазерная технология позволяет создавать структуры больших размеров. Изготовленная в нашей работе методом лазерной абляции периодическая структура имеет коэффициент пропускания, сопоставимый с коэффициентом пропускания периодических структур, полученных другими методами с использованием более дорогостоящих вспомогательных материалов и оборудования [11].

\section{Финансирование работы}

Работа выполнена при финансовой поддержке Министерства науки и высшего образования Российской Федерации в рамках государственного задания № 07052020-0032.

\section{Конфликт интересов}

Авторы заявляют, что у них нет конфликта интересов.

\section{Список литературы}

[1] H.-G. Park, G.-S. Heo, S.-G. Park, H.-C. Jeong, J.H. Lee, D.-S. Seo. ECS Solid State Letters, 4(10), 50 (2015). DOI: $10.1149 / 2.0031510 \mathrm{ssl}$

[2] M. Vineeth. Fabrication of OLED on FTO and ITO coated Substrates [Электронный pecypc]. URL: https://www.researchgate.net/publication/ 234037466_Paper_Fabrication_of_OLED_on_FTO_an d_ITO_coated_substrates

[3] S. Hong, J. Yeo, G. Kim, D. Kim, H. Lee, J. Kwon, H. Lee, P. Lee, S.H. Ko. ACS Nano, 7 (6), 5024-31 (2013). DOI: $10.1021 / \mathrm{nn} 400432 \mathrm{z}$

[4] Свободная энциклопедия [Электронный ресурс]. URL: https://wikichi.ru/wiki/Transparent_conducting_film
[5] V.V. Matylitsky, H. Huber, J.A. der Au. Mechanism of selective removal of transparent conductive oxide layers. Femtosecond-vs. Picosecond-laser pulse ablation [Электронный ресурс]. URL:

https://www.researchgate.net/publication/ 287245043_Mechanism_of_selective_removal_of_tran sparent_conductive_oxide_layers_Femtosecond_vs_Picosecond-laser_pulse_ablation

[6] S. Krause, P.T. Miclea, F. Steudel, S. Schweizer, G. Seifert. J. Renewable and Sustainable Energy, 6 (1), 011402 (2014). DOI: $10.1063 / 1.4840215$

[7] Q. Wang, B.-j. Li, F. Toor, H. Ding. J. Laser Appl., 31 (2), 022505 (2019). DOI: 10.2351/1.5096085

[8] A.S. Osipkov, M.O. Makeev, E.I. Garsiya, A.A. Filyaev, K.P. Sinyagaeva, D.V. Kirillov, D.S. Ryzhenko, G.Yu. Yurkov. In: IOP Conference Series: Materials Science and Engineering (AMDA, 2021), v. 1060, p. 012007. DOI: 10.1088/1757-899X/1060/1/012007

[9] H. Wu, D. Kong, Z. Ruan, P.-C. Hsu, S. Wang, Z. Yu, T.J. Carney, L. Hu, S. Fan, Y. Cui. Nat. Nanotechnol., 8 (6), 421-425 (2013). DOI: 10.1038/nnano.2013.84

[10] J.A. Jeong, H.K. Kim, J. Kim. Sol. Energy Mater \& Sol. Cells, 125, 113-119 (2014). DOI: 10.1016/j.solmat.2014.03.003

[11] J.Y. Kim, J.S. Park, J.Y. Na, S.K. Kim, D. Kang, T.Y. Seong. Microelectron. Eng., 169, 29-33 (2017). DOI: 10.1016/j.mee.2016.11.015

[12] L.J. Guo, M.-G. Kang. Nanostructured transparent metal electrodes for organic solar cells [Электронный pecypc]. URL: https://spie.org/news/1364-nanostructured-transparentmetal-electrodes-for-organic-solar-cells? $\mathrm{SSO}=1$

[13] Е.Д. Вакс, М.Н. Миленький, Л.Г. Сапрыкин. Практика прецизионной лазерной обработки. ISBN 978-5-94836339-4 (Техносфера, Москва, 2013).

[14] Е.Д. Вакс, И.Ф. Лебёдкин, М.Н. Миленький, Л.Г. Сапрыкин, А.В. Толокнов. Резание металлов излучением мощных волоконных лазеров. ISBN 978-5-94836-427-8 (Техносфера, Москва, 2016).

[15] Технологические прочессы лазерной обработки: учеб. пособие для вузов, под ред. А.Г. Григорьянца. ISBN 57038-2701-9 (Изд-во МГТУ им. Н.Э. Баумана, Москва, 2006).

[16] P.A. Nosov, A.F. Shirankov, A.G. Grigoryants, R.S. Tret'yakov. J. Physics: Conference Series, 584 (1), 012006 (2015). DOI: $10.1088 / 1742-6596 / 584 / 1 / 012006$

[17] П.А. Носов, А.Ф. Ширанков, А.М. Хорохоров, К.И. Зайцев, С.О. Юрченко. Изв. вузов. Физика, 61 (12), 146-152 (2018). 